\title{
Attitude towards Women in Managerial Positions: A study among Undergraduate Students of the University of Ghana
}

\author{
Prince Addai ${ }^{1 *}$, Isaac Nti Ofori ${ }^{2}$, Rona Bioh $^{3}$, John Avor $^{4}$ \\ ${ }^{1}$ Department of Industrial Psychology, University of Fort Hare, P/B X1314, Alice, Republic of South Africa, 5700 \\ ${ }^{2}$ Department of Psychology, Zenith University College, Box TF 511, Trade Fair, Accra \\ ${ }^{3}$ Counselling Department, Vine Christian School, Box KD 714, Kanda, Accra \\ ${ }^{4}$ Teaching Staff, Vine Christian School, Box KD 714, Kanda, Accra
}

\begin{abstract}
Men cannot solely manage all the activities of our institutions; women also play tremendous role in management. However, some people have negative attitude towards women in management positions. The present study examined how gender differences influence attitude towards women in managerial positions. The study also examined whether attitude towards women in managerial positions is determined by the perceived integrity of the women. A total of two hundred (200) undergraduate students of the University of Ghana were selected using convenience sampling to complete the Perception of Integrity Scale and Leadership Scale Inventory. Data was analysed using the independent t-test and the Pearson $r$. Results revealed that females had significantly positive attitude towards women in management than males. Christians had significantly positive attitude towards women in management than Muslims. There was a significantly positive relationship between perception of integrity of women in management and attitude towards women in management. The implication of the study is that perceived attitude towards women is influenced by the integrity of the women.
\end{abstract}

Keywords - attitude; integrity; management; women; perception; gender; religion.

\section{INTRODUCTION}

Women are an inherent part of our society and cannot be neglected. Ironically, society does not seem to appreciate the relevance and the contributions a woman can make. The society tries to restrict the capabilities of a woman (Lunyolo, Ayodo, Tikoko \& Simatwa, 2014). Women continue to aspire to managerial positions in all spheres of governance both in the public and private sectors but most of them are not given the top positions they apply for (Ali, Krantz Gul, Asad, Johansson \& Mogren, 2011). In the political realm, even though great strides have been made, and women's participation in both the freedom struggles and democratic dispensations of many African countries has been remarkable, once elections are conducted, and positions are assigned, one realizes that women are sidelined with mostly men appointed to manage national affairs (Basu, Jayal, Nussbaum \& Tambiah, 2003). However, given the chance, a woman can be very successful and influential in every walk of life they venture into.Historically, management has carried the notion of manliness and the belief that men make better managers than women (Maseko, 2013). That belief is still common in the present society. Although the number of female manageresses has increased, they are often named as an afterthought (Ali, Krantz Gul, Asad, Johansson \& Mogren, 2011). According to Hojgaard (2002), traditionally, the societal conventions regarding gender and management exclude women, and top management is considered as a domain for men. In Ghana and Africa at large, it is understood that men lead and women follow (Grant, 2005). It is not rare in rural villages in Africa to find the man literally walking ahead of the woman. Different reasons may be proffered for this but eventually it illustrates the deeply-held notion of management/leadership as a masculine domain.

There was a time that it was believed that managers were born with certain managerial traits. Roberts and Ullom (1990) lists the traits commonly associated with good management as: effective communication skills, confidence, decision making, action taking, and responsibility, problem solving skills, vision, selfawareness, confidence, task completion, and power. These traits are not only common for men but women as well. Current thinking on management assumes that management can be taught and learned (Sims, 2009). This is the reason why Business Management is been taught at the secondary and tertiary levels of education, hence the many management-training programs (Sims, 2009).

Sufficient evidence seems to indicate that women manage somewhat differently from men (Roth \& Basow, 2004). For instance, a woman who portrays a more participatory 
approach to leadership, is more democratic, allows for power sharing, is more sensitive and permits others to make contributions through delegation (Boatwright \& Egidio, 2003). Women have also been found to manage conflict better than men because of their dominant trait of having better listening skills and being more tolerant and empathic (Boatwright \& Egidio, 2003). While men and women might have different managerial styles, it does not suggest that one is dominant over the other (Daily \& Dalton, 2003). It has been observed that the differences we see in managerial style are partly due to the way men view management as leading, while women see management as facilitating (Eagly \& Karau, 2002).

One major problem facing Africans is the continued lack of gender equality in management. In politics for example, women represent only one in seven parliamentarians worldwide, one in ten cabinet ministers, and one in twenty Governments (Organisation for Economic Co-operation and Development, OECD; 2015). Currently, women participation in national-level parliaments globally is less than $25 \%$. Allied to this, estimates based on the current pace of global change indicate that women will achieve equivalence in parliament a century from now (OECD; 2015). However, upon all the education given on the need to get our females in managerial positions, some people still share negative views about women in managerial positions (Daily \& Dalton, 2003). Multiple factors have contributed toward people's attitude towards women in managerial positions. The reality is that most Africans, specifically Ghanaians do not see women as worthy and capable managers (Basu, Jayal, Nussbaum \& Tambiah, 2003).

One significant factor that influences people's attitude towards women in management is perceived integrity among women manageresses (Bartky, 1990). Integrity is defined as the adherence to a set of values that incorporates honesty and freedom from deception (Cohen, 2011). Haslam and Ryan (2008) in a study outlined integrity in terms of ethics and morality. Ethics refers to our standard of right and wrong. That is what people say they believe is right. On the other hand, morality is our lived standard of right and wrong, that is what we actually do. A candidate's perceived competence is one of the most important characteristics for deciding whether or not to support him or her to occupy the managerial position (Tiedens 2001).

Aside the perception of integrity, religious values and teachings also influence attitude towards women in any managerial role. In some religions, women have been denied leadership roles, they are told to be submissive, religious doctrines are used to control them both in society and the family (Noll, 1998). For example, the Sharia Law entrenched in the Islamic religion prohibits women from being in leadership positions. Women are not even allowed to lead men at the mosque during worship (Grant, 2005). Because of these values and norms, Muslims perceive women in management negatively. Some Christian groups have also traditionally given men the position of authority in marriage (Grant, 2005). This position places women in submissive roles, and typically excludes women from church leadership, especially from formal positions requiring any form of ordination as in the Pentecost Church (Noll, 1998). This also influences the attitude of people towards women in management.

\section{REVIEW OF LITERATURE}

Attitude towards women in management can be explained by the Sexual Objectification Theory (Fredrickson \& Roberts, 1997) which assumes that many women are sexually objectified and treated as an object to be treasured for its use by others. Sexual Objectification arises when a woman's body or parts of the body are singled out and separated from her as a person and she is viewed mainly as a physical object for males to achieve their sexual desire (Bartky, 1990). The theory emphasizes that the negative perception people have about women in management is due to the fact that women are not seen as leaders but as objects to help men to achieve their objectives (Fredrickson \& Roberts, 1997).

Despite a steady increase in the number of women in management, they are still estimated to fill less than $15 \%$ of senior managerial positions in the world (United Nations' report, 2009). This statistics demonstrates that many senior women manageresses work in job settings which are numerically subjugated by men. Many authors have raised the question as to why women are underrepresented as managers in general and as senior managers in particular. Powell (2008) assessed the reason why women are underrepresented in managerial positions and found out that one of the reasons is because people have negative attitude towards women in managerial positions. The negative attitude people have for women in managerial positions according to Powell (2008) is because they underperform when elected as leaders in male-dominated organizations.

Askar and Ahmad (2003) conducted a study to assess the determinants of attitudes toward women in management at various organizations in Kuwait among 278 participants. Findings from the study indicated a significant positive attitude towards women manageresses. Sex of the participants was found to significantly influence attitude towards women in management with females being more supportive to women in managerial roles compared to males. However, 
Deal and Stevenson (1998) found no sex difference in attitude towards women in managerial positions.

Contrary findings have been reported on the impact of religion on attitude towards women in management. For example, Al-Mahrouqi (2010) found a significantly positive attitude towards women in management among Christians compared to Muslims. Similarly, Boland (2013) revealed that the attitude towards women in managerial positions was significantly positive compared to that of Muslims. However, a study by Sanbonmatsu (2002) indicated no significant difference in the attitude among Christians and Muslims towards women in politics. Likewise, Bashevkin (2009) reported no significant difference between Muslims and Christians in attitude towards women in politics.

As a means of promoting more females into the managerial arena, Inglehart and Norris (2009) conducted a study with the purpose of finding out how the general populace perceived female integrity and its relationship with their attitude towards women in managerial positions. The results showed that a significant number of males perceived women in management to have poor integrity compared to the females. This reflected in more males having negative attitude towards women in management compared to females. A positive relationship was found between perception of integrity and positive attitude towards women in management.

Assessing the pertinent literature, the influence of religion has mixed implications on the development of attitude towards women in management, and the attitude towards women in managerial positions among males and females have been inconsistent across cultures (Arkorful, Doe \& Agyemang, 2014). Studies on leadership integrity and attitude towards women in management have also been carried out mostly by past researchers in the Western countries. Due to lack of studies addressing the issue of attitude towards women in management and women integrity in Ghana, it is questionable whether western findings can be applied in non-western contexts, like Ghana. For instance, people in the western countries have an individualistic relationship toward each other whereas people in African countries in general are collective in nature. Therefore, more studies are needed to erase the doubt on the applicability of western studies in the Ghanaian context with regard to attitude formation.

It is based on this that the study was carried out to investigate attitudinal differences of people toward women in managerial positions and to also assess whether attitude towards women is influenced by perception of integrity among female manageresses. The study also assessed how personal characteristics such as religion and gender influence attitude towards women in management. Consequently, the researchers predicted that the attitude of females towards women in management will be significantly positive compared to the attitude of males towards women in management. Also, a significantly positive relationship between perception of integrity among females in management and attitude towards women in management was also predicted. Finally, the researchers also predicted that Christians will have significantly positive attitude towards women in management than Muslims.

\section{METHODOLOGY}

\subsection{Population}

The study employed undergraduate students of the University of Ghana, Legon as the population. The University of Ghana is the oldest and largest of the seven public Universities in Ghana. The population of undergraduate has a wide range of individuals from different socio-economic backgrounds and religious beliefs. The different socio-economic background and religious beliefs of the individuals within the population expose them to develop different attitudes and also have different views on social issues such as the underrepresentation of women in management. Also, the population is convenient and readily available to the researchers. The higher educational background of the population also helped to assess if education has the propensity to shape people's mindset on social issues.

\subsection{Participants}

The convenience sampling technique was used to select a total of two hundred (200) students from the population to serve as the sample for the study. The convenience sampling technique was used because only participants who were readily available and willing to participate in the study were selected. The two hundred (200) respondents consisted of one hundred and twenty (120) males and eighty (80) females between the ages of 18 and 36 years, with a mean age of 21.05. The respondents were selected from the four levels of undergraduate studies namely: Level $100(n=32)$, level $200(n=54)$, level 300 $(n=46)$ and level $400(n=68)$. Out of the total participants, one hundred and fifty-two (152) were Christians whilst forty- eight (48) were Muslims. (See Table 1 for description of the demographic characteristics). 
Table.1: Demographic Distribution of Respondents

\begin{tabular}{llll}
\hline $\begin{array}{l}\text { Demographic } \\
\text { Variables }\end{array}$ & \multicolumn{1}{c}{$\begin{array}{c}\text { Male } \\
(n=120)\end{array}$} & $\begin{array}{c}\text { Female } \\
(n=80)\end{array}$ & $\begin{array}{c}\text { Total } \\
(n=200)\end{array}$ \\
\hline Age & Mean $(S D)$ & Mean $(S D)$ & Mean $(S D)$ \\
& $22.01(2.94)$ & $20.10(2.57)$ & $21.05(2.76)$ \\
Academic Levels & & & \\
Level 100 & 14 & 18 & 32 \\
Level 200 & 29 & 25 & 54 \\
Level 300 & 35 & 11 & 46 \\
Level 400 & 42 & 26 & 68 \\
\hline
\end{tabular}

\subsection{Design}

The study employed a cross-sectional survey in gathering data for describing respondents' attitude towards women in management. The cross-sectional survey was used to seek respondents' views using structured questionnaires. The time dimension of the study was cross-sectional as large amount of data on respondents' attitude towards women in management were collected from among many respondents within a relatively short time.

\subsection{Measures}

Data on perceived integrity and attitude towards women in management were collected using the Perceived Leader Integrity Scale (PLIS; Craig \& Gustafson, 1998) and the Attitude towards Women in Management Scale (AWMS; Rudman \& Kilianski, 2000) respectively.

The PLIS assessed perception of integrity of women in management. The PLIS is a unidimensional factor structure reflecting perceivers' overall impression of a leader's ethical integrity. The PLIS contains thirty (30) items measured on a four-point likert scale ranging: 0 (Not at all), 1 (Barely), 2 (Somewhat) and 3 (Well). Respondents were requested to select only one of the four alternatives. The PLIS has been found valid and reliable, with Cronbach's alpha internal consistency estimates greater than .84 (Craig \& Gustafson, 1998). Total scores ranged from 0 to 90 with higher scores indicating higher level of perceived integrity of women in management. A sample of the items on the PLIS is "Women would deliberately exaggerate people's mistakes to make them look bad to others".

The Attitude towards Women in Management Scale (AWMS) measures attitude people have towards women in managerial positions. The scale consists of fifteen (15) items measured on a five-point Likert scale ranging: 4 (Strongly Agree), 3 (Agree), 2 (No Idea), 1 (Disagree) and 0 (Strongly Disagree). Reliability coefficient of .75 was reported by Rudman and Kilianski (2000). Scores ranging from 0 to 60 were awarded with $0-30$ depicting negative attitude and 31 to 60 depicting positive attitude towards women in managerial positions. Some items on the scale include: "Women should be allowed to be leaders if they have the qualities," "When a man is there a woman should not be in management" "Even though women can be in management, they cannot perform effectively as men."

\subsection{Procedure for Data Collection}

Every undergraduate student at the main campus of the University of Ghana was legible to take part in the study. The researchers approached the respondents in their lecture halls and also in their halls of residence. Respondents were told the purpose was to study factors influencing women in management. After consenting, respondents were interviewed to know their level in the university before taking part in the study. This was to ensure that all the participants were undergraduate students of the University of Ghana. Approximately 25 minutes was used by each respondent to complete the questionnaire. It took the researchers two weeks in collecting the data.

\section{DATA ANALYSIS}

The data was collated and analyzed using the version 20 of the Statistical Package for Social Science. Descriptive and inferential statistics were used for the analysis. The inferential statistics (Pearson Product Moment Correlation Coefficient and Independent t-test) were used for analyzing the three predictions. The difference in attitude towards women in management between males and females was analyzed using the independent t-test (see Table 2). The Pearson Product Moment Correlation Coefficient was used to compute the relationship between perceived women integrity and attitude towards women in management (see Table 3). The independent t-test was again used to compute the significant differences in scores on attitude towards women in management among Christians and Muslims (see Table 4).

\section{RESULTS}

The study was interested in testing three main hypotheses. These hypotheses were:

1. The attitude of females towards women in management will be significantly positive 
compared to the attitude of males towards women in management.

2. There will be a significantly positive relationship between perception of integrity among females in management and attitude towards women in management.

3. Christians will have significantly positive attitude towards women in management than Muslims.

The first and third hypotheses were analyzed using the independent t-test. This is because the differences in attitude towards women in management between two groups were compared. The dependent variable (attitude towards women in management) was also measured on an interval scale. The second hypothesis was analysed using the Pearson Product Moment Correlation Coefficient because the relationship between two variables (perceived women integrity and attitude towards women in management) was established with each of the variable measured on an interval scale.

Table.2: Gender Differences in Attitude towards Women in Management

\begin{tabular}{lcccccc}
\hline Gender & $\mathrm{N}$ & Mean & SD & df & $t$ & $P$ \\
\hline Males & 120 & 43.35 & 7.67 & 198 & -1.077 & .283 \\
Females & 80 & 44.53 & 7.44 & & & \\
\hline
\end{tabular}

The results of the study shown in Table 2 revealed no significant gender difference in attitude towards women in management $\left(t_{(198)}=-1.077, p=.283\right)$. This stands to reason means that, attitude towards women in management among males $(M=43.35, S D=7.67)$ was not significantly different from that of females $(M=44.53, S D=7.44)$. (See Table 2).

Table.3: Relationship between Perceived Integrity and Attitude towards Women in Politics

\begin{tabular}{llcc}
\hline & Variable & r-value & $\mathrm{p}$ \\
\hline 1 & Perceived Women Integrity & .464 & .000 \\
2 & Attitude & & \\
\hline
\end{tabular}

The findings of the study indicate that a significant positive relationship exists between perception of integrity and attitude towards women in management $(\mathrm{r}=.464, p<.05)$. This means that the higher the perception of integrity among women in management, the more positive the attitude towards women in management. (See Table 3).

Table.4: Influence of Religion on Attitude towards Women in Management

\begin{tabular}{lcccccc}
\hline Religion & $\mathrm{N}$ & Mean & SD & Df & $t$ & $P$ \\
\hline Christianity & 152 & 47.03 & 5.03 & 198 & 16.183 & .000 \\
Islamic & 48 & 33.66 & 4.84 & & & \\
\hline
\end{tabular}

The results shown in Table 4 indicate that there is a significant impact of religion on attitude towards women in management $\left(t_{(198)}=16.183, p<.05\right)$. This means that Christians have a significant positive attitude $(\mathrm{M}=47.03, \mathrm{SD}=5.03)$ towards women in management than Muslims $(M=33.66, \mathrm{SD}=4.84)$. (See Table 4).

\section{DISCUSSION AND RECOMMENDATIONS}

The results of the study indicated no sex difference in attitude towards women in management. In other words, the prediction that the attitude of females towards women in management will be significantly positive compared to the attitude of males towards women in management was not supported. This finding suggests that among the undergraduate university students, males do not differ significantly from females in terms of their attitude towards women in management. This finding is congruent with previous findings that found no significant difference between males and females in terms of attitudes toward women in management (Deal \& Stevenson, 1998; Stoker, Velde \& Lammers, 2012).

A possible explanation one can offer with respect to the lack of a significant difference between males and females on scores of attitude towards women in management is because of the higher educational attainment of the participants. Education helps enlighten people's views and make them develop objective attitudes about issues. 
Personal biases diminish to some extent when people acquire higher education. Because of the higher educational attainment among males, their personal biases have diminished to an extent that they view females as good manageresses just as females perceive themselves. Moreover, universities tend to engage diverse students of both sexes who engage in regular intellectual discussions. This has a greater propensity of shaping the attitude of both males and females on social issues such as attitude towards women in management.

The study also found that perceived integrity among women in management was positively associated with positive attitude towards women in management. This supports the prediction that a significantly positive relationship between perception of integrity among females in management and attitude towards women in management. This finding indicates that when people perceive women as having higher integrity (higher ethics and morality), they develop positive attitudes and agree to women taking part in managerial roles.

The significant positive relationship between perceived integrity among females in management and attitude towards women in management corroborates earlier studies that indicated that the higher the perception of integrity of women in management, the more positive the attitude towards women in management (Haslam \& Ryan, 2008; Inglehart \& Norris, 2009). A similar view was held by Duggar (2010) who stipulated that integrity is a means of perceiving someone as competent. When an individual adheres to a set of values that incorporates honesty and freedom from deception, they are seen as such and their capability of pursuing a specific task is seen positively. According to Cohen (2011), a major factor that determines positive attitude towards leaders is their sense of honesty and freedom from deception which is a major component of integrity. Haslam and Ryan (2008) found out that when women are perceived as having higher levels of integrity, attitude towards them become more positive and people tend to appreciate their capabilities.

Also, Quigley (2007) found that participants who perceived higher integrity among women in leadership tend to have positive attitude towards women in leadership compared to those who perceived lower integrity among women in leadership. Quigley (2007) explained that leaders are evaluated based on their personal morality and probity. When a leader is perceived as having higher morality and probity, people perceive them as capable and develop positive attitude towards them. This explains why a significantly positive attitude was found between perception of integrity and attitude towards women in management.

Finally, the study found that Christians have significantly positive attitude towards women in management than
Muslims. This means that Christians have favourable attitude and agree to women taking part in management compared to males. This supported the researchers' prediction that Christians will have a significantly more positive attitude towards women in management than Muslims.

The significant positive attitude of Christians towards women in management compared to Muslims is in agreement with previous studies (e.g., Al-Mahrouqi, 2010; Boland, 2013) which found Christians to have positive attitude towards women manageress and allow women to occupy managerial positions compared to Muslims. Noll (1998) have offered support to this finding by explaining that unlike Christians, Muslims treat women as more inferior to men. Women have been denied leadership roles, they are told to be submissive, and religious doctrines are used to control them by the Muslims unlike the Christians. Muslims sharia Law rooted in the Islamic religion prohibits women from even being religious leaders. Because of the values and norms of the Islamic religion, its members that have internalized the values of the religion develop negative attitude towards women in all managerial roles.

This study had some limitations that must be taken into account when interpreting its findings. First of all, research on attitudes involves several methodological difficulties that may possibly lead to biases (Etzersdorfer \& Sonneck, 1998). Certainly, in a study on topic such as attitude towards women, it is hard to avoid biases from women respondents who are the subjects of discussion in this study. Secondly, the study relied only on self-report data which is subjective in nature (Schwarz, 1999). The use of self-report measure may be also faulty because participants might have different experiences with privacy issues that could influence their attitude which are not reported with the self-report measure. Moreover, selection of participants was based on convenient sampling which makes it doubtful in generalizing the findings to the larger population.

Aside the flaws, the study had some implications worthy of speaking to. The findings of the study imply that males hold similar attitude towards women in management as females and so males no longer ridicule women as good leaders as perceived in the olden days. However, religious values determine significantly the attitude of the public towards issues such as women in management. The findings also provide additional evidence that attitude towards women in management is determined more by cognitive factors such as perception of integrity of the women in management position. Therefore, when people see women as capable, they will also support them in their managerial roles. 
Based on the significant influence of religion on attitude toward women in management, the researchers recommend the need to target religion as a means of changing social issues such as attitude towards women in management. This will be a reliable way of achieving desired attitudes. Again, women are encouraged to demonstrate a sense of integrity for people to support them in their managerial roles. The general public is also advised to give an objective judgement about women before developing an undesirable attitude towards them. Finally, future research should continue to explore the factors that influence attitude formation as a means of shaping the attitude of the general public on social issues. The following recommendations may also be offered for further studies: Firstly, there is the need for future researchers to delve deeper into the underlying factors that contribute to the developing of attitude towards women in management. This can be made better by the use of qualitative study. Secondly, there is also the need to employ participants with diverse levels of educational backgrounds that will allow a researcher to clearly identify whether educational background influences the development of attitude towards women in management. This could be achieved by the inclusion of students from junior high school, senior high school and tertiary institutions in a single study. Lastly, future researchers can also make comparisons between respondents with no formal education and those with formal education to provide a clear view on the influence of education on attitude towards social issues.

\section{CONCLUSION}

The findings of this study have established that males and females do not differ in their attitude towards women in managerial positions. There was a significantly positive relationship between perception of integrity among females in management and attitude towards women in management. Christians were found to have significantly positive attitude towards women in management than Muslims. There was also no sex difference in attitude towards women in management. The findings imply that the sorts of attitude we develop towards women in management is determined more by our educational attainment and the perceived integrity of the woman in management. The lack of gender differences in attitude towards women in management suggests that males and females might be influenced by the changing trend of events in our society and the diligence by which women are now going through their managerial roles. Again, interacting with both sexes with different capacities in the university might help in shaping the extent to which both males and females develop different attitudes towards each other.

\section{REFERENCES}

[1] Ali, T. S., Krantz G., Gul, R., Asad, N., Johansson, E. \& Mogren, I. (2011). Gender roles and their influence on life prospects for women in urban Karachi, Pakistan: a qualitative study. Glob Health Action, 4(10): $3402-3413$

[2] AL-Mahrouqi, A. (2010). Attitudes towards and Perceptions of Women Managers and Their Communication Competencies in the Sultanate of Oman. Unpublished Master's Thesis submitted to the University of Waikato, Hamilton, New Zealand. Retrieved from http://hdl.handle.net/10289/4991

[3] Arkorful, H. K., Doe, F. \& Agyemang, C. B. (2014). Attitude of Private and Public Sector Employees towards Female Managers in Ghana. International Journal of Human, 12: 124 - 128

[4] Askar, H. \& Ahmad, M. (2003). Campus involvement in leadership among African American students. College Student Affairs Journal, 21(2): 5367.

[5] Bartky, S. L. (1990). Femininity and Domination: Studies in the Phenomenology of Oppression. Psychology Press, 8: 141 - 149

[6] Bashevkin, S. (2009). Women, Power, Politics: The Hidden Story of Canadas Unfinished Democracy. Don Mills: Oxford University Press.

[7] Basu, A., Jayal, N. G., Nussbaum, M. \& Tambiah, Y. (2003). Essays on Gender and Governance. India: Human Development Resource Center, United Nations Development Programme.

[8] Boatwright, K. J., \& Egidio, R. K. (2003). Psychological predictors of college women's leadership aspirations. Journal of College Student Development, 44(5), 653-669.

[9] Boland, C. (2013). Islamic feminism: Fighting discrimination, inspired by faith. Retrieved from http://www.yourmiddleeast.com/columns/article/isla micfeminism-fighting-discrimination-inspired-byfaith 11257

[10]Cohen, W. A. (2011). Heroic Leadership: Leading with Integrity and Honor. Jossey-Bass

[11]Craig, S. B. \& Gustafson, S. B. (1998). Perceived Leader Integrity Scale: An Instrument for Assessing Employee Perceptions of Leader Integrity. Leadership Quarterly, 9(2): 143-144.

[12] Daily, C. M., \& Dalton, D. R. (2003). Women in the Boardroom: A Business Imperative. Journal of Business Strategy, 24 (5): 8 - 9.

[13] Deal, J. J. \& Stevenson, M. A. (1998). Perceptions of Female and Male Managers in the 1990s. Sex Roles, 38: 287 - 300 . 
[14]Eagly, A. H. \& Karau, S. J. (2002). Role Congruity Theory of Prejudice Toward Female Leaders. Psychological Review, 109(3): 573 - 598.

[15]Etzersdorfer E, Sonneck G (1998) Preventing suicide by influencing mass-media reporting. The Viennese experience 1980-1996. Arch Suicide Res, 4: 67-74.

[16]Fredrickson, B. L. \& Roberts, T. (1997). Objectification Theory. Toward Understanding Women's Lived Experiences and Mental Health Risks. Psychology of Women Quarterly, 21(2): 173 206.

[17]Grant, H. (2005). Women role as leaders. The Journal of Psychology, 95(2), 199 - 204.

[18] Haslam, S. A., \& Ryan, M. K. (2008). The road to the glass cliff: Differences in the perceived suitability of men and women for leadership positions in succeeding and failing organizations. The Leadership Quarterly, 19: 530 - 546.

[19] Helfat, C. E., Harris, D. \& Wolfson P. J. (2006). Women and Men in the Top Executive Ranks of U.S. Corporations. Academy of Management Perspectives, 20 (4): 42-64.

[20]Hojgaard, L. (2002). Tracing Differentiation in Leadership: An Analysis of Differences in Gender Composition in Top Management in Business, Politics and the Civil Service. Gender, Work and Organization 9 (1): 35-48.

[21] Inglehart, R. \& Norris (2009). Muslim Integration into Western Cultures: Between Origins and Destinations. HKS Faculty Research Working Paper Series, RWP09-007.

[22]Lunyolo, G. H., Ayodo, T. O. M., Tikoko, B. \& Simatwa, E. M. W. (2014). Socio-cultural Factors that Hinder Women's Access to Management Positions in Government Grant Aided Secondary Schools in Uganda: The Case of Eastern Region. Educational Research, 5(7): 241 - 250,

[23] Maseko, T. I. (2013). A Comparative Study of Challenges Faced By Women in Leadership: A Case of Foskor and The Department Of Labour In Mhlathuze Municipality. A Dissertation submitted in accordance with the requirement for the degree of Masters in Commerce in the Faculty of Commerce, Administration and Law at University of Zululand.

[24] Noll, M. (1998). The Bible and Slavery. In Religion and the American Civil War, ed. Randall M. Miller, 43-73. New York and Oxford: Oxford University Press.

[25] Organisation for Economic Co-operation and Development (OECD; 2015). Women in politics in Government at a Glance. OECD Publishing, Paris.
[26] Powell, J. (2008). How college affects students: A third decade of research. San Francisco, CA: JosseyBass Publishers.

[27]Quigley, J. H. (2007). Trust - An Essential Asset: Creating Individual and Corporate Value. The Raytheon Lectureship in Business Ethics. Waltham: Bentley College.

[28] Roberts, D. \& Ullom, C. (1990). Student leadership program model. College Park, MD: National Clearinghouse for Leadership programs. Journal of Managerial Psychology, 12(2): 285 - 420

[29] Roth, A. \&Basow, S. A. (2004) Femininity, Sports, and Feminism. Developing a Theory of Physical Liberation. Journal of Sport and Social Issues, $28(3) ; 245-265$.

[30] Rudman, L.A. \& Kilianski, S.E. (2000). Implicit and explicit attitudes toward female authority. Personality and Social Psychology Bulletin, 26: 1315-1328.

[31] Sanbonmatsu, K. (2002). Gender stereotypes and vote choice. American Journal of Political Science, 46: 20-34.

[32] Schwarz, N. (1999). Self-reports: How the questions shape the answers. American Psychologist, 54, 93105.

[33] Sims JM. (2009). Styles and qualities of effective leaders. Dimens Crit Care Nursing, 28(6): 272 - 276.

[34] Stoker, J. I. Velde, M. V. \& Lammers, J (2012). Factors Relating to Managerial Stereotypes: The Role of Gender of the Employee and the Manager and Management Gender Ratio. Journal of Business Psychology, 27(1): $31-42$.

[35] Tiedens, L. Z. (2001). Anger and Advancement Versus Sadness and Subjugation: The Effect of Negative Emotion Expressions on Social Status Conferral. Journal of Personality and Social Psychology, 80(1), 86 - 94.

[36] United Nations Report (2009). The Status of Women in the United Nations Systems and in the Secretariat. www.un.org/womenwatch/osagi/pdf/factsheet-UNsystem-vs-UN-secretariat-dec-2010-data.pdf (accessed 2 October 2012). 